\title{
Take back the meaning of term illness
}

Previously published at www.cmaj.ca

$\mathrm{W}$

hen physicians and their patients understand different meanings for commonly used medical terms, there is real danger of miscommunication. Current use of the term "illness" is an important case in point. It is curious and disturbing to hear from medical students over the past two decades that they are being taught and asked to accept something about this term that is not related to its origin or its prevalent usage. It goes like this: The disease is what has gone awry with the patient's body; the illness is the person's reaction to or experience of that disease. There are two errors in this teaching. The "is" in those statements implies a definition, but typically students are not offered a formal definition. Furthermore, illness as a term is already taken.

Ordinary people use the term correctly, as they have for at least half a millennium. Illness is the comfortable, familiar and meaningful word used to denote unwellness in general: someone has fallen ill; another has died of a chronic illness.

How did this etymologic thievery come about in our medical schools? Credit is generally given in the literature to Irwin Kleinman. ${ }^{1}$ In a parenthetical statement, he writes that illness is "the human experience of sickness." In a later book, he states, "By invoking the term illness, I mean to conjure up the innately human experience of symptoms and suffering." ${ }^{2}$ This merely declarative appropriation is astonishing and naive. Can our profession be so weak-kneed as to yield a central term in our everyday practice simply because one of us says it should be so? What is the truth about the term illness?

Illness derives from the Middle English adjective ill, which in turn is from

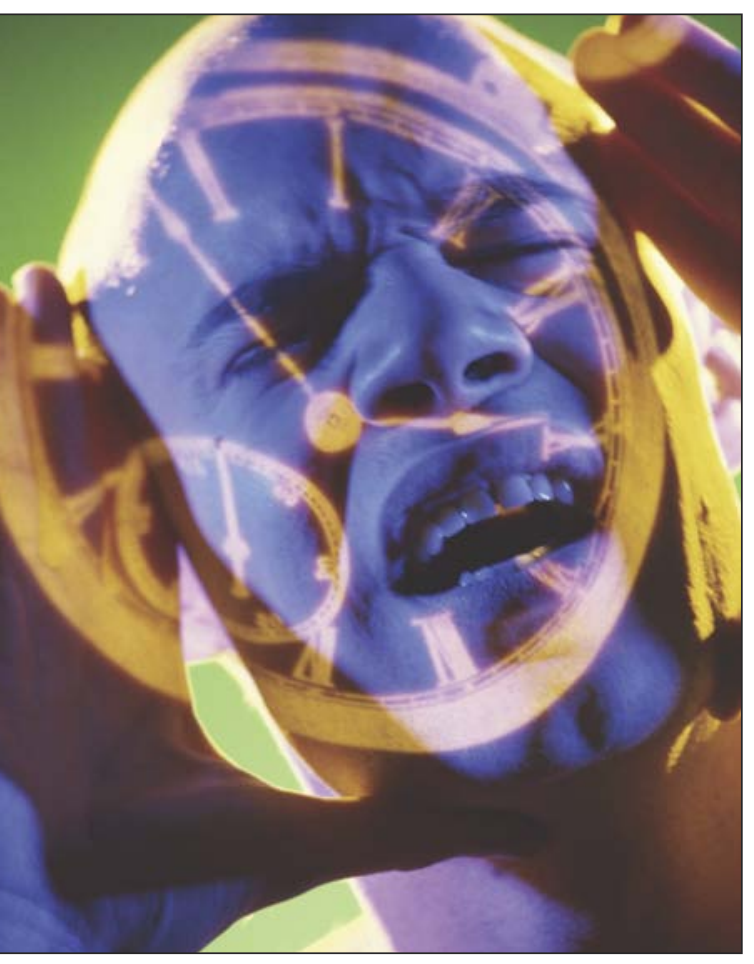

that there is no other suitable existing word. When Kleinman ascribed his new meaning to illness, he failed to consider whether there was already a familiar term for the impact of the illness on the person.

There is such a word: suffering. In his enduring essay on the meaning of suffering, Cassel sums it up clearly and convincingly: "Suffering is experienced by persons, not merely by bodies, and has its source in challenges that threaten the intactness of the person as a complex social and psychological entity." ${ }^{5}$

The only thing more difficult to eradicate than a lie, once it is cast broadly about, is the truth. So it is with the meaning of the term 'illness.' Illness, and its types, are difficult to discuss because they are abstract concepts. The meaning of the term

the Old Norse term illr (bad, not related to evil) whose origin is, in turn, lost in the mists of time.

Now, consider how illness has been used over the centuries in medical practice. A colleague and I have submitted scholarly arguments that identify the following exhaustive set of human somatic abnormalities: disease, defect and injury. ${ }^{3}$ For each of these terms, we have proposed definitions that fit with logic and established usage: disease is an anomalous somatic process; defect, an anomalous somatic state, and injury, a somatic anomaly inflicted extrinsically. Generally, in English, when we have a set of terms, there is a collective noun referring to the concept of that set. In this case, there seems to be no term more obvious than "illness." Illness, then, would be defined as any somatic anomaly that can manifest to bother or make sick the affected person. ${ }^{4}$

Those who propose a change in our time-honoured use of an important word in medical practice have to prove that it serves no present purpose and has been clear for a long time. Let's keep it. Let's say what we mean.

\section{Ken Flegel MDCM MSc}

Senior Associate Editor

CMAJ

Ottawa, Ont.

\section{REFERENCES}

1. Kleinman A, Eisenberg L, Good B. Culture, illness and care. Clinical lessons from anthropologic and cross-cultural research. Ann Intern Med 1978;88. 251-8.

2. Kleinman A. The meaning of symptoms and disorders. In: The illness narratives. New York (NY): Basic Books; 1988. p. 3.

3. Miettinen OS, Flegel K. Elementary concepts of medicine: V. Disease: one of the main subtypes of illness. J Eval Clin Pract 2003;9:321-3.

4. Miettinen OS, Flegel K. Elementary concepts of medicine: III. Illness: somatic anomaly with.. J Eval Clin Pract 2003;9:315-7.

5. Cassel EJ. The nature of suffering and the goals of medicine. N Engl J Med 1982;306:639-45.

Do you have an opinion about this article? Post your views at www.cmaj.ca. Potential Salon contributors are welcome to send a query to salon@ cmaj.ca. 